\title{
Fatal bronchiolitis obliterans associated with chrysotherapy
}

\author{
LINN HOLNESS, JERRY TENENBAUM, NOEL B. E. COOTER, \\ AND RONALD F. GROSSMAN
}

From the Departments of Medicine and Pathology, Mount Sinai Hospital and the University of Toronto

SUMmARY We describe a patient who developed fatal bronchiolitis obliterans following gold therapy and review the relationship between rheumatoid arthritis and bronchiolitis.

Various pulmonary complications of rheumatoid arthritis have been described. They include interstitial fibrosis, necrobiotic nodules, pleural effusions, Caplan's syndrome, and pulmonary vascular disease. ${ }^{1}$ Moreover, studies of pulmonary function in rheumatoid patients have included accounts of airways obstruction, ${ }^{2}$ and, rarely, bronchiolitis obliterans has been described. ${ }^{3-5}$ Pulmonary reactions are also associated with gold salts and penicillamine, which are used to treat rheumatoid arthritis. Gold therapy is thought to cause interstitial pneumonitis, ${ }^{6-16}$ and penicillamine has been linked with bronchiolitis obliterans. ${ }^{17}{ }^{18}$ This report describes a patient with rheumatoid arthritis who developed fatal bronchiolitis obliterans after gold therapy.

\section{Case report}

A 65-year-old woman was admitted to hospital in April 1981 with increasing dyspnoea. In 1975 she developed polyarthritis, principally involving her hands, and was treated for 5 years with acetylsalicylic acid and a variety of nonsteroidal anti-inflammatory drugs including fenoprofen, ketoprofen, naproxen, and ibuprofen. In June 1980 her arthritic symptoms intensified, with increasing swelling and longer morning stiffness. The rheumatoid factor was positive to a dilution of $1: 1280$ and the ESR was $49 \mathrm{~mm} /$ hour (Westergren). Acetylsalicylic acid and naproxen were continued and gold treatment was begun. She received $25 \mathrm{mg}$ of sodium aurothiomalate (Myocrisin) and then $50 \mathrm{mg}$ every week for 15 weeks followed by $50 \mathrm{mg}$ every 2 weeks.

Accepted for publication 4 October 1982.

Correspondence to Dr R. F. Grossman, Mount Sinai Hospital, Suite 427, 600 University Avenue, Toronto, Ontario, Canada M5G 1 X5.
Her past history included phlebitis 27 years previously, hypothyroidism, angina, atrial fibrillation, and temporal lobe epilepsy. Treatment, in addition to anti-inflammatory agents, included thyroxine, digoxin, frusemide, spironolactone, and primidone, all of which she had been taking for at least 3 years. She was a nonsmoker. She was a school teacher and she had no relevant occupational exposures.

In the autumn of 1980 mild exertional dyspnoea was noted. It increased gradually until February 1981, when wheezing was detected. At this time the gold injections were discontinued. A total dose of $1125 \mathrm{mg}$ had been administered. No side effects were noted during the treatment. Her white blood cell count remained around $4 \times 10^{\%} / 1$, which it had been prior to the gold, and her ESR had decreased to 11 .

Treatment with salbutamol and theophylline was begun, with slight improvement in symptoms initially. By mid-March the dyspnoea began to increase again, and cough productive of small amounts of white sputum began. The dyspnoea rapidly progressed, resulting in severe limitation. By the beginning of April she was bedridden. Other complaints were weakness and a weight loss of $15 \mathrm{lb}(6.8 \mathrm{~kg})$.

On admission the heart rate was 100 ; blood pressure was $150 / 90 \mathrm{mmHg}$ with $15 \mathrm{~mm}$ of pulsus paradoxus and a respiratory rate of 38 . The thyroid was palpable. There was diffuse wheezing on auscultation, and the breath sounds were markedly decreased. The cardiovascular and abdominal systems were normal. Initial laboratory investigations revealed a haemoglobin of $16 \cdot 2 \mathrm{~g} / \mathrm{dl}$, leucocytes $10.1 \times 10^{\%} / 1$, with $90 \%$ polymorphs and $5 \%$ bands, ESR $3 \mathrm{~mm} / \mathrm{h}$, electrolytes normal, blood urea nitrogen $5.7 \mathrm{mmol} / \mathrm{l}$ (normal $3-6.5 \mathrm{mmol} / \mathrm{l}$ ), creatinine $132.6 \mu \mathrm{mol} / \mathrm{l}$ (normal $50-110 \mu \mathrm{mol} / \mathrm{l}$ ), rheumatoid factor positive $1: 160$. The chest $x$-ray showed hyperinflation, and no parenchymal infiltrates were seen 


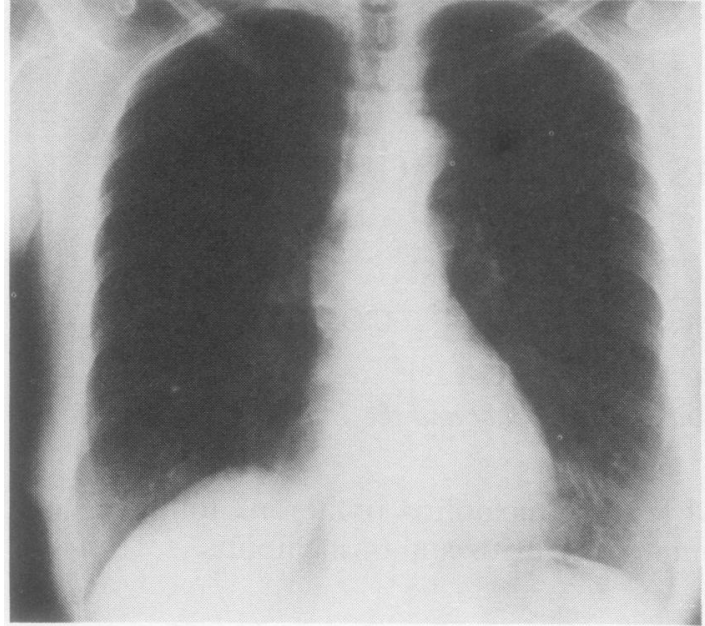

Fig. 1A

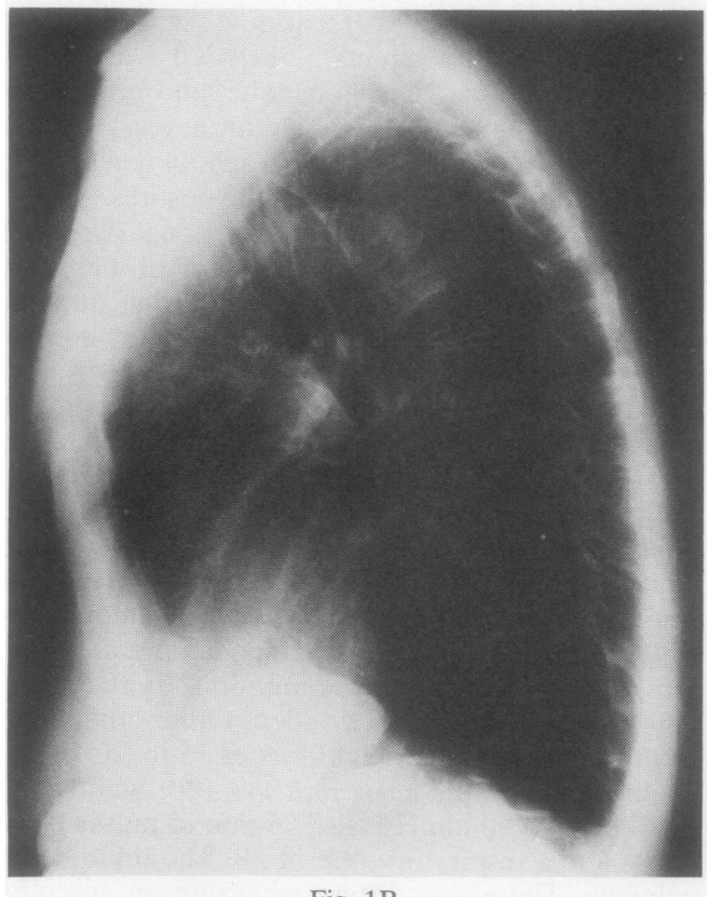

Fig. 1B

Fig. 1 Postero-lateral and lateral chest roentgenograms on admission showing only hyperinflation without pulmonary infiltrates.

(Figs 1A, B). There was no retrosternal compression of the trachea by her thyroid gland. The electrocardiogram showed sinus rhythm, with a QRS of 0.07 $\mathrm{s}, \mathrm{PR}$ of $0.16 \mathrm{~s}$, and some T wave flattening. Sputum cultures were negative. Arterial blood gases on room air included $\mathrm{pH} 7.41, \mathrm{PCO}_{2} 5.9 \mathrm{kPa}$ (normal 4.4-5.9 $\mathrm{kPa}$ ), $\mathrm{Po}_{2} 7 \cdot 2 \mathrm{kPa}$ (normal $10-14 \mathrm{kPa}$ ), $\mathrm{TCO}_{2} 27$ $\mathrm{mmol} / \mathrm{l}$, and on $35 \%$ oxygen $\mathrm{pH} 7.46, \mathrm{PCO}_{2} 4.8 \mathrm{kPa}$, $\mathrm{Po}_{2} 13.8 \mathrm{kPa}, \mathrm{TcO}_{2} 25 \mathrm{mmol} / \mathrm{l}$. Because of concern about pulmonary emboli (dyspnoea, hypoxaemia, history of venous disease) a pulmonary angiogram was performed and was normal.

Initial treatment consisted of oxygen, intravenous hydrocortisone sodium succinate, and aminophylline, and salbutamol by inhalation. In spite of this vigorous bronchodilator therapy profound dyspnoea persisted, and there was no improvement in pulmonary function results (Table 1 ).

On 1 May 1981 her dyspnoea increased, and blood gases on $35 \%$ oxygen were $\mathrm{pH} 7.25, \mathrm{PcO}_{2} 8.6 \mathrm{kPa}$, $\mathrm{Po}_{2} 11.7 \mathrm{kPa}, \mathrm{TCO}_{2} 28 \mathrm{mmol} / \mathrm{l}$. Later in the day she had a respiratory arrest and resuscitation efforts were unsuccessful.

Autopsy revealed bilateral widespread bronchiolitis, mild bilateral bronchopneumonia, bilateral mild nephrosclerosis, end-stage thyroiditis, atherosclerosis, and cholelithiasis. Examination of the lungs revealed mucous plugging of bronchioles and focal ulceration of the respiratory mucosa. Association with the plugs was a bronchiolitis characterised by peribronchiolar infiltration by lymphocytes and histiocytes. There were occasional collections of histiocytes within the airways. Some of the mucous plugs also showed an admixture of acute inflammatory cells. In addition there were scattered foci of bronchopneumonia associated with the areas of mucous plugging. A representative section is shown in Figs 2A, B.

\section{Discussion}

This patient had seropositive rheumatoid arthritis with no apparent lung involvement prior to gold therapy. After gold injections her joint symptoms improved, but progressive airway obstruction developed. Death resulted from widespread obliterative bronchiolitis. She had no known exposure to toxins usually associated with bronchiolitis obliterans, nor had she had a symptomatic viral infection. Since her rheumatoid disease was well controlled with gold therapy, it seems unlikely that the progressive bronchiolitis obliterans was simply an extraarticular manifestation of her rheumatoid disease. Her respiratory symptoms began only after the initiation of chrysotherapy, implicating gold at least temporally as an aetiological agent.

Bronchiolitis obliterans has been linked to both rheumatoid arthritis and therapy with penicillamine. It has been described in patients with rheumatoid disease who have received neither gold nor penicil- 
Table 1 Pulmonary function results

\begin{tabular}{|c|c|c|c|c|c|}
\hline & \multirow[t]{2}{*}{ Predicted } & \multicolumn{2}{|c|}{16 April 1981} & \multicolumn{2}{|c|}{27 April 1981} \\
\hline & & Observed & \% Predicted & Observed & \% Predicted \\
\hline Total lung capacity (l) & $4 \cdot 1$ & - & - & $7 \cdot 3$ & 178 \\
\hline Vital capacity (1) & $2 \cdot 4$ & $1 \cdot 3$ & 54 & 1.4 & 58 \\
\hline Residual vol. (l) & $1 \cdot 6$ & - & - & 5.9 & 369 \\
\hline Forced expired vol. in $1 \mathrm{~s} \mathrm{(l)}$ & 1.8 & 0.5 & 28 & 0.5 & 28 \\
\hline Flow rate at $50 \%$ forced $\mathrm{VC}(1 / \mathrm{s})$ & $2 \cdot 4$ & $0 \cdot 3$ & 13 & 0.2 & 8 \\
\hline Flow rate at $25 \%$ forced VC (1/s) & $1 \cdot 2$ & $0 \cdot 2$ & 17 & 0.2 & 17 \\
\hline Airway resistance (RAW) $\mathrm{cmH}_{2} \mathrm{O} / 1 / \mathrm{s}$ & $0 \cdot 5$ & - & - & $6 \cdot 2$ & 1240 \\
\hline Lung diffusion $(\mathrm{ml} / \mathrm{min} / \mathrm{mmHg}$ ) & $20 \cdot 6$ & - & - & $13 \cdot 2$ & 64 \\
\hline
\end{tabular}

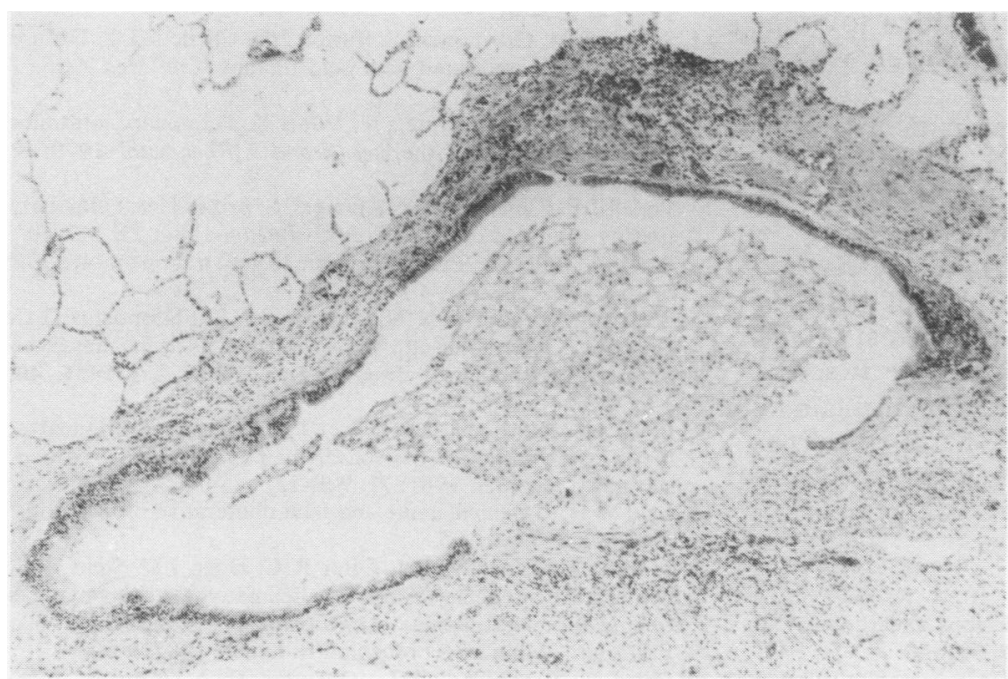

Fig. 2A

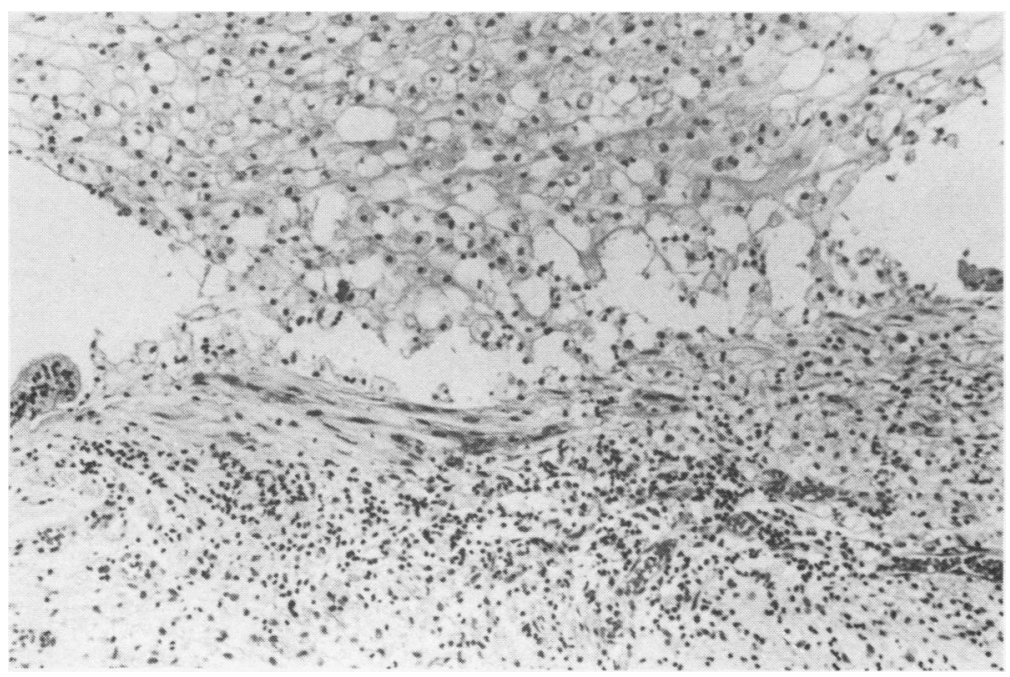

Fig. 2B
Fig. 2A Pulmonary bronchiole. Note the mucus plugging, focal ulceration of the respiratory mucosa, and peribronchial inflammation. The surrounding lung parenchyma is normal. $(\times 47)$.

Fig. 2B Same bronchiole. Note the mucosal disruption and peribronchial infiltration by lymphocytes and histiocytes. (×116). 
lamine ${ }^{4}$ in rheumatoid patients treated with penicillamine (one case in a woman treated with gold approximately 8 years prior to penicillamine therapy), ${ }^{4718}$ and in one patient with cystinuria ${ }^{17}$ treated with penicillamine. Unlike the interstitial lung disease associated with gold therapy the outcome in patients with bronchiolitis is not favourable. However, a trial of corticosteroid therapy with careful monitoring of pulmonary function has been suggested. ${ }^{19}$ Most either succumb to the disease or are left with respiratory impairment. ${ }^{17-21}$ It has been suggested that the mechanism of injury involves both the underlying disease and treatment. Patients with connective tissue disease may be more prone to bronchiolitis, and the penicillamine may interfere with or alter the healing process. ${ }^{19}$

It is impossible to know if our patient's bronchiolitis obliterans was related solely to her rheumatoid disease or to gold therapy. It may be that both were necessary, with the gold salts acting to precipitate the disease process. Further investigation is required to separate the relationship between rheumatoid disease, the drugs given to treat it, and bronchiolitis obliterans. In the meantime it seems prudent to monitor patients on gold or penicillamine therapy for rheumatoid arthritis and to stop the drugs if any evidence of lung disease develops.

\section{References}

1 Walker W C, Wright V. Pulmonary lesions and rheumatoid arthritis. Medicine (Baltimore) 1968; 47: 501-20.

2 Geddes D M, Webley M, Emerson P A. Airways obstruction in rheumatoid arthritis. Ann Rheum Dis 1979; 38: 222-5.

3 Herzog C A, Miller R R, Hoidal J R. Bronchiolitis and rheumatoid arthritis. Am Rev Respir Dis 1981; 124: 636-9.

4 Geddes D M, Corrin B, Brewerton D A. Davies R J, TurnerWarwick M. Progressive airway obliteration in adults and its association with rheumatoid diseases. $Q J$ Med 1977; 184: 427-44.

5 Gosink B B, Friedman P J, Liebow A A. Bronchiolitis obliterans: roentgenologic-pathologic correlation. $A J R$ 1973; 117: 816-32.

6 Winterbauer R H, Wilske K R, Wheelis R F. Diffuse pulmonary injury associated with gold treatment. $N$ Engl J Med 1976; 294: 919-21.

7 Miyachi S. Pulmonary reaction to chrysotherapy. N Engl J Med 1976; 295: 506.

8 Geddes D, Brostoff J. Pulmonary reaction to chrysotherapy. $N$ Engl J Med 1976; 295: 506-7.

9 Alarcon G S, Gotuzzo E. Pulmonary reaction to chrysotherapy. N Engl J Med 1976; 295: 507.

10 Gould P W, McCormack P L, Palmer D G. Pulmonary damage associated with sodium aurothiomalate therapy. $J$ Rheumatol 1977; 4: 252-60.

11 Sepuya S M, Grzybowski S, Burton J D, Clement J G. Diffuse lung changes associated with gold therapy. Can Med Assoc J 1978; 118: 816-8.

12 Tala E, Jalava S, Nurmela T, Vuori K. Pulmonary infiltrates associated with gold therapy. Scand J Rheumatol 1979; 8: 97-100.

13 Podell T E, Klinenberg J R, Kramer L S, Brown H V. Pulmonary toxicity with gold therapy. Arthritis Rheum 1980; 23: 347-50.

14 Smith W, Ball G V. Lung injury due to gold treatment. Arthritis Rheum 1980; 23: 351-4.

15 Scott D L, Bradby G V H, Aitman T J, Zaphiropoulos G C, Hawkins C F. Relationship of gold and penicillamine therapy to diffuse interstitial lung disease. Ann Rheum Dis 1981; 40: 136-41.

16 Levinson M L, Lynch J P, Bower J S. Reversal of progressive, life-threatening gold hypersensitivity pneumonitis by corticosteroids. Am J Med 1981; 71: 908-12.

17 Lyle W H. D-penicillamine and fatal obliterative bronchiolitis. Br Med J 1977; i: 105

18 Murphy K C, Atkins C J, Offer R C, Hogg J C, Stein H B. Obliterative bronchiolitis in two rheumatoid arthritis patients treated with penicillamine. Arthritis Rheum 1981; 24: 557-60.

19 Editorial. Obliterative bronchiolitis. Lancet 1982; i: 603-4.

20 Epler G R, Snider G L, Gaensler E A, Cathcart E S, Fitzgerald M X, Carrington C B. Bronchiolitis and bronchitis in connective tissue disease. JAMA 1979; 242: 528-32.

21 Stein H B, Patterson A C, Offer R C, Aitkens C J, Teufel A, Robinson H S. Adverse effects of D-penicillamine in rheumatoid arthritis. Ann Intern Med 1980; 92: 24-9. 